\title{
Comparison of virulence, reproductive potential, and persistence among local Heterorhabditis indica populations for the control of Temnorhynchus baal (Reiche \& Saulcy) (Coleoptera: Scarabaeidae) in Egypt
}

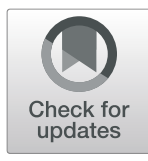

\author{
Ibrahim E. Shehata', Mostafa M. A. Hammam², Fahiem E. El-Borai ${ }^{3,4}$, Larry W. Duncan ${ }^{3}$ and \\ Mahfouz M. M. Abd-Elgawad ${ }^{*}$
}

\begin{abstract}
The scarab beetle, Temnorhynchus baal (Reiche \& Saulcy) (Coleoptera: Scarabaeidae), becomes a key pest of strawberry, especially after increasing its cultivated area and economic importance in Egypt. Few entomopathogenic nematode (EPN) species/strains were tested against this pest, where only a foreign species had good effect comparable to the native populations tested previously. Thirty-eight indigenous Heterorhabditis indica populations were tested against the most damaging, third instar larvae of $\mathrm{H}$. baal in two soil types, where strawberry cultivation prevails. The corrected mortality induced by indigenous $H$. indica population in $T$. baal larvae was (99.52 and 98.57\%) for 15 populations in the sandy soil and 23 in loamy sand soil, respectively. Overall average of infective juveniles (IJS) per T. baal larva was about $(41,000)$. The average of emerged nematode-IJs from the infected grubs for the 15 EPN populations in sandy soil, $(46,960 \mathrm{JJ} / \mathrm{grub})$, was significantly $(P<0.001)$ higher than that $(36,502 \mathrm{IJs} / \mathrm{grub})$ of $23 \mathrm{EPN}$ populations in loamy sand soil. The insignificant difference was detected in the reproductive capacity among nematode populations in T. baal larvae in sandy or loamy sand soil. A highly significant difference was found among total IJ numbers collected 10,18,26, and 30 days post-inoculation in sandy or loamy sand soil. The persistence of the $\mathrm{H}$. indica populations in the soil varied greatly. Obtained results suggest further use of at least ten populations of such indigenous nematodes under field conditions.
\end{abstract}

Keywords: Biocontrol, Entomopathogenic nematodes, Beneficial traits, Scarab beetle

\section{Background}

Strawberry, Fragaria ananassa Duchesne, cultivated area in Egypt has highly expanded in recent years. Early fruiting, long harvest season, good quality, low production costs, and closeness of export markets offer good opportunities (Abd-Elgawad 2019). Egypt occupied the fourth largest producer of strawberries in the world in 2017 (FAO 2019). In Egypt, strawberry pests and diseases that were not of economic importance have spread and are threatening the productivity of the crop. Among those

\footnotetext{
*Correspondence: mahfouzian2000@yahoo.com

2Plant Pathology Department, National Research Centre, El-Behoos St., Dokki, Giza 12622, Egypt

Full list of author information is available at the end of the article
}

pests, the strawberry white grub or rootgrub (Temnorhynchus baal Reiche \& Saulcy) (Coleoptera: Scarabaeidae) ranks high. The serious phytophagous immature stages of $T$. baal cause heavy economic losses to strawberry in Egypt (El-Shemy et al. 2013). Like other scarabaeids, T. baal larvae undergo subterranean life and therefore their control is difficult. On the other hand, because of the problems associated with environmental and regulatory concerns due to the excessive use of chemical insecticides, research on developing alternative control strategies is desperately needed. In this vein, entomopathogenic nematodes (EPNs) are known to infect the soil-dwelling development stages of insect pests since soil is their basic habitat. So, the grubs are 
excellent candidates for biocontrol by EPNs (e.g., Koppenhöfer and Fuzy 2008; Abdel-Razek and Abd-Elgawad 2013 and Kajuga et al. 2018). They are one of the potential alternatives worldwide and in Egypt (Abd-Elgawad 2017a, 2017b). Nematode genera Heterorhabditis and Steinernema with their mutualistic bacteria Photorhabdus spp. and Xenorhabdus spp., respectively, have been commercially used against many economically important insect pests worldwide (MMM et al. 2017). Steinernematids are amphimictic, whereas heterorhabditids are hermaphroditic. Infective juveniles (IJs), the only free-living stage, penetrate into the hemocoel of their hosts, usually through the gut or spiracles. Heterorhabditids have a dorsal tooth that might also facilitate penetration in other areas (e.g., intersegmental membranes). Then, mutualistic bacteria from the nematode's digestive system are released within the insect host, and the host dies from septicemia, usually within 24-72 h. The nematodes feed, develop, mate, and reproduce within the host cadaver, and, often after multiple generations, IJs are again produced and leave the cadaver to seek new hosts (Kaya and Stock 1997). Biological control via EPNs has been particularly successful against certain insect species that spend a large portion of their life cycle in the soil, particularly the strawberry white grub, T. baal (Shamseldean and Atwa 2004; Atwa 2009 and Atwa and Hassan 2014).

However, research on the potential of EPNs to suppress T. baal has been limited. Only few EPN species/strains have been tested for pathogenicity to $T$. baal larvae, which are usually found in the soil and therefore are potential targets. A few indigenous and introduced EPNs have been used for biocontrol of T. baal larvae. Foreign EPN strains were more effective (Shamseldean and Atwa 2004; Atwa 2009 and Atwa and Hassan 2014) but indigenous nematodes are more appreciated because they are likely more adaptive without any risk to Egyptian fauna and flora. So, laboratory testing of additional species/isolates may lead to the identification of nematodes with superior beneficial traits for biocontrol of T. baal.

The study primary objective was to determine the relative susceptibility of $T$. baal larvae to 38 indigenous isolates of $H$. indica under laboratory conditions. Also, the reproductive potential of the nematodes in $T$. baal as well as IJs persistence in two soil types that are common for growing strawberry in Egypt were investigated.

\section{Materials and methods}

Thirty-seven EPN isolates were obtained from soil planted with citrus alone or mixed with mango trees from seven locations in July, 2017, and additional six isolates were extracted from 5 other locations in August, 2017, both surveys were at Giza Governorate, Egypt. So, a total of 43 EPN isolates were identified herein according to the morphological and molecular tests as $H$. indica. Nematode-infective juveniles (IJs) of these 43 EPN populations were reared in vivo, via the greater wax moth (Galleria mellonella L.) last instar larvae at $24 \pm 2{ }^{\circ} \mathrm{C}$. After 3 cycles in G. mellonella, the IJ culturing and harvesting procedures (Kaya and Stock 1997) could only maintain 38 isolates, which were separately kept in 500-ml flasks containing approximately $150 \mathrm{ml}$ distilled water at $12^{\circ} \mathrm{C}$. In order to avoid anoxic conditions for the IJs, their suspensions were aerated almost weekly by an aquarium oxygenator. The IJs were used within a week after harvesting of the last cycle, when the nematode survival was checked first by observing their mobility under stereomicroscope (Majić et al. 2019).

The grub (T. baal) larvae were collected from strawberry field at Arab El-Ghadeer, Tukh district, El-Qalioubia Governorate, Egypt, via tracking a plow, driven by the tractor, to gather them at season-end late in March. Active and full grown T. baal third instar larvae were identified (Voglar et al. 2019) and selected in the laboratory to test them for the nematode-IJ virulence and reproductive potential. Two types of soil similar to those were selected from which EPNs were isolated, i.e., each isolate was tested in a soil similar to that isolated from it. Four larvae were placed over $250 \mathrm{~g}$ soil within each plastic semi-cone cup $(12.8 \mathrm{~cm}$ diam., $9 \mathrm{~cm}$ height with perforated lids), and 4 cups were used as a replicate for each EPN population. A total of $640 \mathrm{~T}$. baal larvae were used for 40 treatments; 38 nematode populations and 2 untreated cups as checks (without nematodes) for the 2 soil types in a completely randomized block design. One day was left for the grubs to penetrate the cup soil before adding (2000 IJs in $5 \mathrm{ml}$ ) water on the soil surface within a cup at room temperature $\left(27 \pm 5^{\circ} \mathrm{C}\right.$ and $65 \%$ $\mathrm{RH})$. Soon, the cups were delicately shacked handily to distribute the nematodes within the soil. Such a test was carried out in each of two 10\% moistened sterilized soil types; sandy (sand $88.8 \%$, silt $4 \%$, clay $7.2 \%, \mathrm{pH} 7.7$, $\mathrm{CaCO} 31.88 \%$, OM $0.68 \%$ ) and loamy sand (sand 82.8 , silt 6, clay 11.2, pH 7.8, $\mathrm{CaCO} 313.8 \%$, OM 8.7\%) soil. Both soil types were collected from strawberry field plots; sandy soil from Badr district, El-Beheira Governorate and loamy sand from Tukh district, El-Qalioubia Governorate, Egypt. Five days after the addition of IJs, EPN infectiousness to the grubs was screened where the grubs were transferred to White traps (Kaya and Stock 1997). The infectiousness was defined here as the insect mortality caused by EPNs. Therefore, all data were corrected in order to compensate for natural mortality by Abbott's formula (Abbott 1925). For each nematode population, each infected T. baal larva was placed on a White trap, where IJs were collected every other day, starting 10 days after IJs addition, until emergence ceased or was considered negligible (30 days post-inoculation). At 
each collection time, the number of IJs produced per insect was determined through dilution counts (Kaya and Stock 1997). Soon after getting the grubs out of the cups, 4 G. mellonella last instar larvae were replaced the grubs per cup to test the persistence of the remaining EPNs. There were 4 insects also in each replicate (cup) with 4 cups for each check of the soil types (16 insects/check). About 2-3 days later, G. mellonella cadavers exhibiting the characteristic signs and symptoms of EPN infection were transferred to modified White traps (Kaya and Stock 1997). The IJs emerging in the traps were used to reinfect additional Galleria to confirm pathogenicity and to fulfill Koch's postulates (Pelczar and Reid 1972). Addition of new G. mellonella larvae to replace previous ones in these cups was done for 3 additional times so typically that infected G. mellonella cadavers were counted also after 1, 2, and 3 months post-inoculation of IJs.

For EPN identification, nematode-IJs were concentrated in approximately $(200 \mu \mathrm{l})$ water in Eppendorf Centrifuge tube and DNA was extracted, using the Ul$\operatorname{traClean}^{\text {Tx }}$ Soil DNA Extraction Kit (MoBio). All the samples were checked for quality and quantity using $1 \mu \mathrm{l}$ per duplicate in a Nanodrop ND-1000 v3.3.0 (Thermo Scientific, Wilmington, DE) and adjusted to the appropriate concentration, $0.2 \mathrm{ng} \mu \mathrm{l}$. Species-specific primers and TaqMan probes were used to conduct real time PCR according to the protocols and conditions described by Atkins et al. (2005) and Campos-Herrera et al. (2011). Optical 96-well reaction plates (USA Scientific, Orlando, FL, USA) were used on an ABI Prism 7000 (Applied Biosystems) for the qPCR identification. The reactions were carried out in duplicate in a final volume of $20 \mu \mathrm{l}$, using $1 \mu \mathrm{l}$ of the corresponding DNA template, $10 \mu \mathrm{l}$ of Master Mix (Applied Biosystems, manufactured by Roche, Branchburg, NJ, USA), and the appropriate concentration of primers and probe. Sterile de-ionized water as a negative control instead of template DNA and a positive control from pure identified EPN species corresponding to its standard curve as described by Campos-Herrera et al. (2011) was used.

\section{Statistical analysis}

An analysis of variance (ANOVA) was used to analyze the data of nematode virulence, reproductive capacity, and persistence among nematode populations. A comparison of means was done using Duncan's new multiple range test (DNMRT). The average of emerging IJ numbers in the 2 soil types were compared by the two-tailed Student's $t$ test. Because of using original counts of nematodes with aggregated distribution violates assumptions necessary for parametric statistical analysis, transformed nematode counts, $\log _{10}(X+1)$, were subjected to the analysis.

\section{Results and discussion}

\section{Comparing virulence and reproductive potential among nematodes}

Each of the tested EPN populations attained high percentage mortality in the scarab grub (Table 1). Averages ( \pm standard errors) of nematode-induced mortality in $T$. baal larvae were $(99.58 \pm 0.42$ and $98.64 \pm 0.55 \%)$ for 15 EPN populations in sandy soil and 23 populations in loamy sand soil, respectively. The corresponding corrected mortality was (99.52 and $98.57 \%$ ), respectively. Insignificant difference in virulence was detected among nematode populations in sandy $(F=1 ; \mathrm{df}=14 ; P=0.47)$, or loamy sand $(F=1 ; \mathrm{df}=22 ; P=0.48)$ soil. The highest numbers of IJs emerging from the grub cadavers were obtained at 14, 16 and 18 post-inoculation days (Fig. 1). Emerging IJs were counted every other day (Fig. 1) but Table 1 contains combined data at 10, 18, 26, and 30 days. An infected grub cadaver produced a total of about 41,300 to 59,700 and 32,300 to 41,300 IJs per T. baal larva at 30 days post-inoculation in sandy and in loamy sand soil, respectively. Overall average of IJs per T. baal larva was about (41000). Based on $t$ test, the average of such emerged IJs for the 15 EPN populations in sandy soil $(46,960 \mathrm{IJs} /$ grub) was significantly $(P<0.001)$ higher than that of 23 EPN populations in loamy sand soil (36,502 IJs/grub). Insignificant difference was detected in reproductive capacity among nematode populations in T. baal larvae in sandy $(F=1.39 ; \mathrm{df}=14 ; P=0.20)$ or loamy sand $(F=0.87 ; \mathrm{df}=22 ; \quad P=0.64)$ soil. Highly significant difference was found among total IJ numbers collected 10,18,26, and 30 days post-inoculation in sandy ( $F=664.3 ; \mathrm{df}=14 ; P=2.12 \mathrm{E}-35 ;$ Fig. 2$)$ or loamy sand $(F=2080.8 ; \mathrm{df}=22 ; P=2.9 \mathrm{E}-65$; Fig. 3$)$ soil.

\section{Persistence in the nematode populations}

Since the percentage mortality of grubs was similar in both soil types, the efficacy of remained EPN populations in the cups was pooled together for further calculations of virulence against G. mellonella larvae at extended periods as an evidence of nematode persistence in soil. Over a period of 3 months in soil, the number of infected G. mellonella larvae varied greatly $(F=8.64 ; \mathrm{df}=37 ; P=3.98 \mathrm{E}$ -19) according to the applied nematode population (Table 2). These infected larvae ranged from 15.6 to $56.3 \%$. In a descending order, the following code numbers of $H$. indica populations caused greater mortality and could persist longer in the soil compared to others: 25, 21, $44,5,33,22,6 / 2,47,18 / 2,20$. Nematode persistence, measured by ability to infect $G$. mellonella larvae in soil at extended baiting times, significantly $(P \leq 0.05)$ differed among the tested periods (Fig. 4). Only about 3\% of G. mellonella larvae in soil were infected at 3 months post-inoculation. 
Table 1 Mortality of Temnorhynchus baal larvae after exposure to different populations of Heterorhabditis indica and numbers of emerging nematode-infective juveniles using 2 different types of soil as substrates (mean of four replicates (cups) each has four insects. The control has the grubs without nematodes)

\begin{tabular}{|c|c|c|c|c|c|c|c|c|}
\hline \multirow{3}{*}{$\begin{array}{l}\text { H. indica } \\
\text { population } \\
\text { code }\end{array}$} & \multirow[t]{3}{*}{ Soil type } & \multirow{2}{*}{\multicolumn{2}{|c|}{$\begin{array}{l}\text { Mortalities of } T \text {. baal larvae } \\
\text { ( } 5 \text { days post-treatment) }\end{array}$}} & \multicolumn{5}{|c|}{ Number of emerging nematode-infective juveniles/grub larva } \\
\hline & & & & \multicolumn{5}{|c|}{ Days of post-infestation } \\
\hline & & Mean \pm SE & Mortality \% & $\begin{array}{l}10 \text { days } \\
\text { (7 April 2018) }\end{array}$ & $\begin{array}{l}18 \text { days } \\
\text { (15 April 2018) }\end{array}$ & $\begin{array}{l}26 \text { days } \\
\text { (23 April 2018) }\end{array}$ & $\begin{array}{l}30 \text { days } \\
\text { (1 May 2018) }\end{array}$ & $\begin{array}{l}\text { Total IJs } \\
\text { rate/larva }\end{array}$ \\
\hline 20 & Sandy & $4 \pm 0$ & 100 & 324 & 39,606 & 4522 & 4 & 44,456 \\
\hline 16 & Loamy sand & $3.75 \pm 0.43$ & 93.75 & 294 & 36,005 & 1455 & 0 & 37,754 \\
\hline 46 & Loamy sand & $3.75 \pm 0.43$ & 93.75 & 199 & 33,855 & 1460 & 0 & 35,514 \\
\hline 15 & Loamy sand & $3.75 \pm 0.43$ & 93.75 & 124 & 35,864 & 1328 & 0 & 37,316 \\
\hline 17 & Loamy sand & $3.75 \pm 0.43$ & 93.75 & 151 & 38,157 & 1457 & 0 & 39,765 \\
\hline 32 & Loamy sand & $3.75 \pm 0.43$ & 93.75 & 102 & 30,787 & 1405 & 0 & 32,294 \\
\hline 19 & Loamy sand & $4 \pm 0$ & 100 & 114 & 30,228 & 2492 & 0 & 32,834 \\
\hline 18 & Loamy sand & $4 \pm 0$ & 100 & 127 & 32,363 & 1437 & 0 & 33,927 \\
\hline 35 & Loamy sand & $4 \pm 0$ & 100 & 131 & 31,148 & 1491 & 2 & 32,772 \\
\hline 33 & Sandy & $4 \pm 0$ & 100 & 211 & 37,455 & 3640 & 0 & 41,306 \\
\hline 27 & Loamy sand & $4 \pm 0$ & 100 & 100 & 30,515 & 2462 & 0 & 33,077 \\
\hline 26 & Loamy sand & $4 \pm 0$ & 100 & 187 & 31,356 & 1487 & 0 & 33,030 \\
\hline 39 & Sandy & $4 \pm 0$ & 100 & 174 & 36,718 & 7669 & 17 & 44,578 \\
\hline $37 / 2$ & Sandy & $4 \pm 0$ & 100 & 155 & 38,987 & 2528 & 0 & 41,670 \\
\hline 31 & Sandy & $4 \pm 0$ & 100 & 389 & 41,018 & 12,575 & 3 & 53,985 \\
\hline $4 / / 2$ & Sandy & $4 \pm 0$ & 100 & 166 & 42,757 & 1573 & 2 & 44,498 \\
\hline 34 & Loamy sand & $4 \pm 0$ & 100 & 103 & 34,036 & 1438 & 5 & 35,582 \\
\hline 5 & Sandy & $4 \pm 0$ & 100 & 129 & 44,308 & 3588 & 7 & 48,032 \\
\hline 44 & Sandy & $4 \pm 0$ & 100 & 209 & 43,817 & 2554 & 9 & 46,589 \\
\hline 48 & Loamy sand & $4 \pm 0$ & 100 & 151 & 36,834 & 1701 & 2 & 38,688 \\
\hline 11 & Loamy sand & $4 \pm 0$ & 100 & 101 & 39,789 & 1448 & 0 & 41,338 \\
\hline $18 / 2$ & Sandy & $4 \pm 0$ & 100 & 156 & 44,393 & 4172 & 0 & 48,721 \\
\hline 47 & Sandy & $4 \pm 0$ & 100 & 177 & 43,688 & 15,812 & 0 & 59,677 \\
\hline 60 & Sandy & $4 \pm 0$ & 100 & 188 & 42,540 & 2773 & 0 & 45,501 \\
\hline $40 / 2$ & Loamy sand & $4 \pm 0$ & 100 & 114 & 34,334 & 2295 & 0 & 36,743 \\
\hline 41 & Loamy sand & $4 \pm 0$ & 100 & 107 & 37,599 & 1826 & 0 & 39,532 \\
\hline 40 & Loamy sand & $4 \pm 0$ & 100 & 122 & 35,288 & 1368 & 0 & 36,778 \\
\hline 21 & Sandy & $4 \pm 0$ & 100 & 184 & 43,585 & 3229 & 0 & 46,998 \\
\hline $6 / / 2$ & Sandy & $4 \pm 0$ & 100 & 177 & 42,715 & 2856 & 0 & 45,748 \\
\hline 50 & Loamy sand & $4 \pm 0$ & 100 & 218 & 38,150 & 1560 & 0 & 39,928 \\
\hline 22 & Sandy & $4 \pm 0$ & 100 & 139 & 41,894 & 2778 & 7 & 44,818 \\
\hline 43 & Loamy sand & $4 \pm 0$ & 100 & 190 & 35,828 & 2816 & 2 & 38,836 \\
\hline 25 & Sandy & $3.75 \pm 0.43$ & 93.75 & 248 & 41,196 & 9491 & 8 & 50,943 \\
\hline 58 & Loamy sand & $4 \pm 0$ & 100 & 112 & 38,005 & 805 & 0 & 38,922 \\
\hline 7 & Loamy sand & $4 \pm 0$ & 100 & 110 & 34,113 & 1632 & 11 & 35,866 \\
\hline 38 & Loamy sand & $4 \pm 0$ & 100 & 97 & 37,989 & 1470 & 9 & 39,565 \\
\hline 29 & Loamy sand & $4 \pm 0$ & 100 & 162 & 33,661 & 1534 & 0 & 35,357 \\
\hline 6 & Loamy sand & $4 \pm 0$ & 100 & 137 & 34,702 & 1519 & 0 & 36,358 \\
\hline Control 1 & Loamy sand & $0.25 \pm 0.43$ & 6.25 & 0 & 0 & 0 & 0 & 0 \\
\hline Control 2 & Sandy & $0.5 \pm 0.5$ & 12.5 & 0 & 0 & 0 & 0 & 0 \\
\hline
\end{tabular}




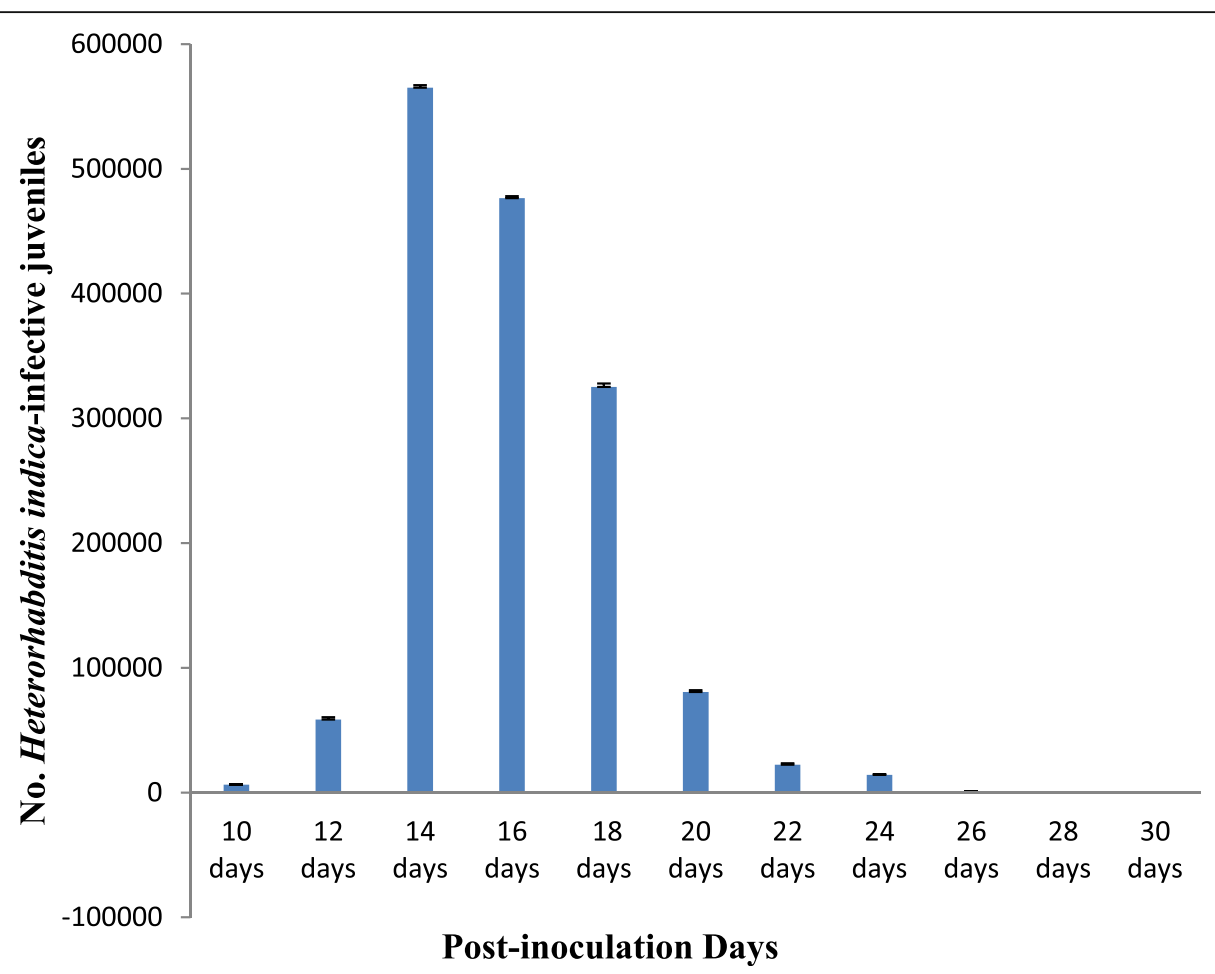

Fig. 1 Total numbers of nematode-infective juveniles for 38 nematode populations emerging from Temnorhynchus baal larvae at different days

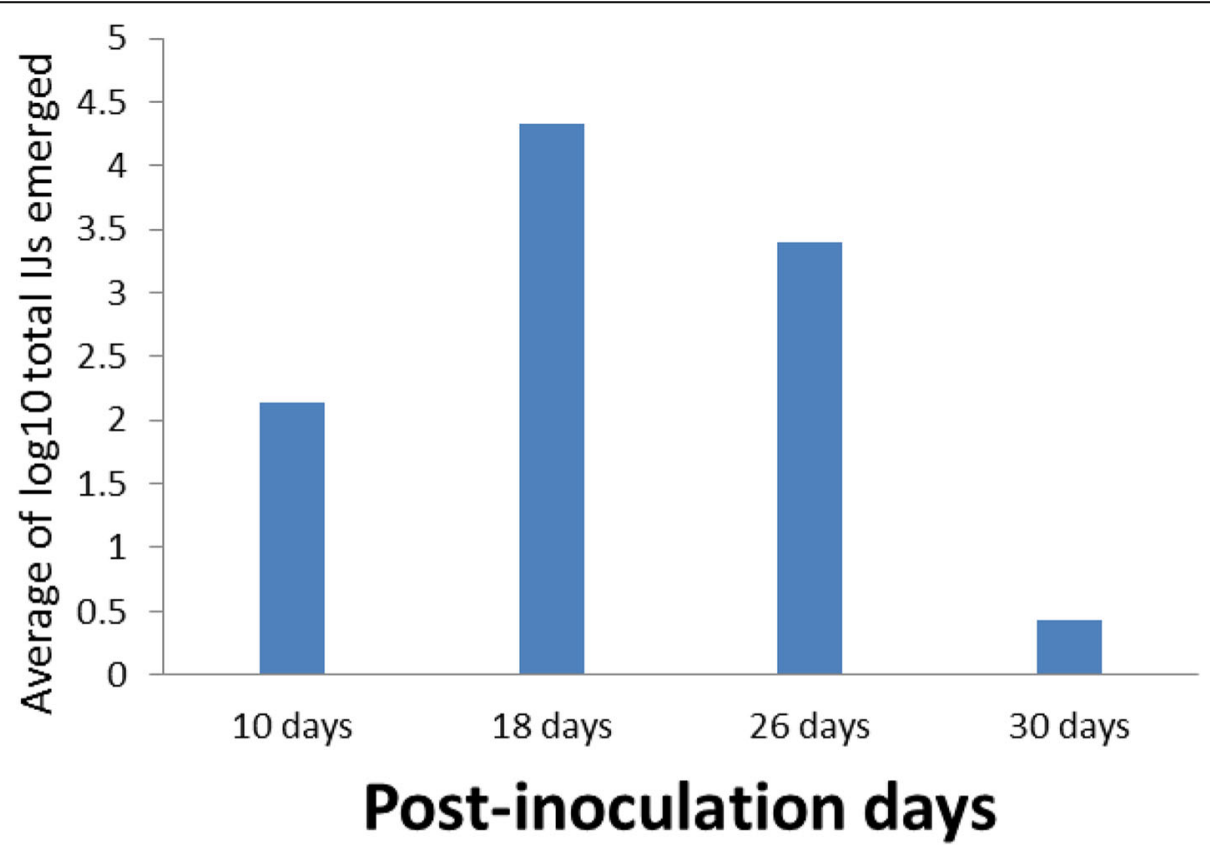

Fig. 2 Average numbers of emerging infective juveniles (IJs)/ Temnorhynchus baal larva for 15 Heterorhabditis indica populations in sandy soil. Numbers among all post-inoculation days are significantly $(P \leq 0.05)$ different according to DNMRT 


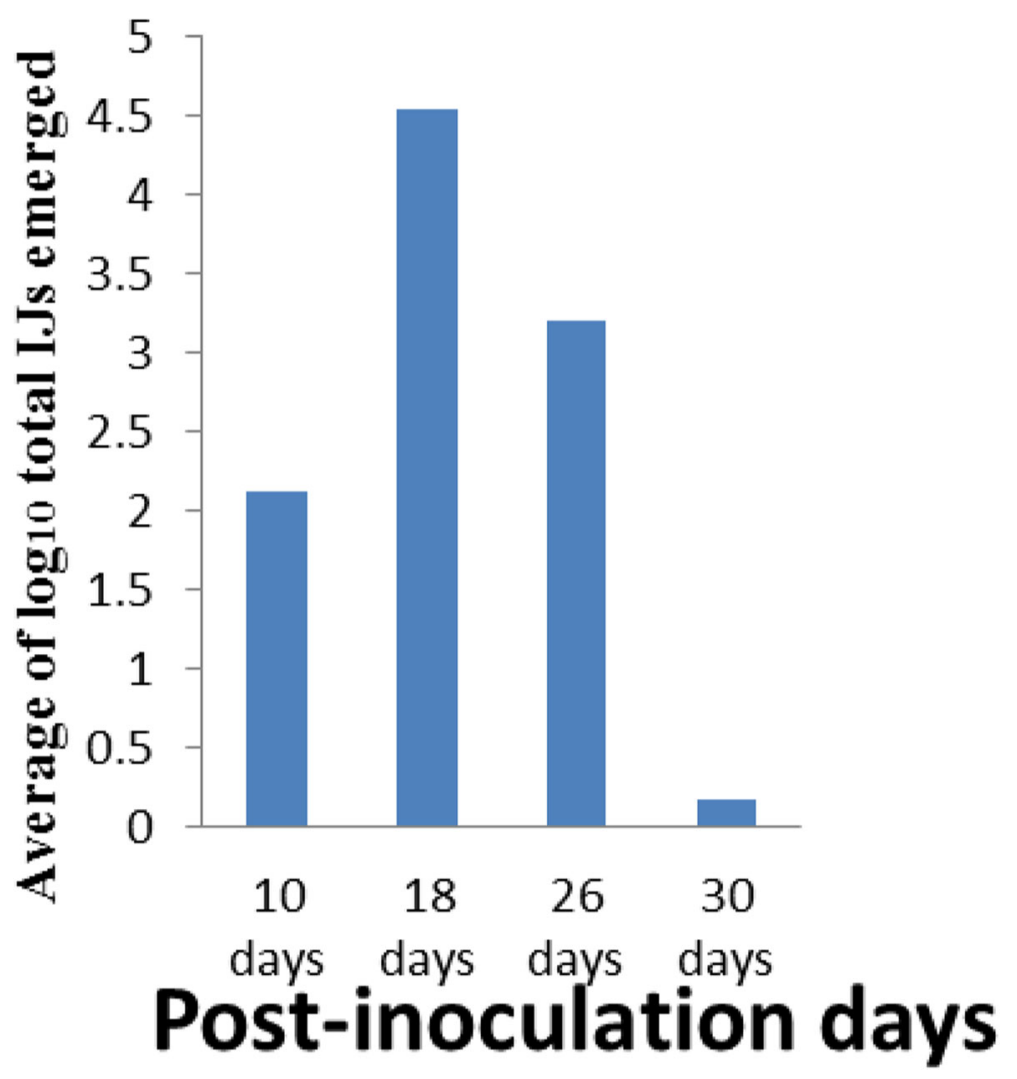

Fig. 3 Average numbers of emerging infective juveniles (IJs)/ Temnorhynchus baal larva for 23 Heterorhabditis indica populations in loamy sand soil. Numbers among all post-inoculation days are significantly $(P \leq 0.05)$ different according to DNMRT

Initially, since a nematode population comprises individuals that inhabit a specific unit of substratum (Caveness 1964), the primary thrust was to examine the novel populations herein to look for any new nematode strain which is a subgroup within a species differing in one or more of such significant traits as virulence and reproductive potential within the third instar larvae of T. baal, and/or persistence from the rest of the species. Significant beneficial traits have been recorded to differ among strains within an EPN species, e.g., virulence (Griffin 2015; Baiocchi et al. 2017), reproductive potential (Testa and Shields 2017; Abd-Elgawad 2017a), persistence (Shields 2015), and environmental tolerance (Somasekhar et al. 2002). Therefore, studies to estimate fitness and quality of nematodes reared in $T$. baal such as measuring nematode viability (percentage of emerged living infective juveniles), infectivity (power to invade), reproductive capacity (yield per insect), and virulence (power to kill) (Abd-Elgawad et al. 2012) could upgrade the grub biocontrol.

Also, Somasekhar et al. (2002) examined virulence and reproductive potential among 14 freshly isolated natural populations of Steinernema carpocapsae and got significant variations among these traits. However, the present investigation diverged from that of Somasekhar et al. (2002) as the virulence tests targeted a specific pest ( $T$. baal) whereas their virulence tests used the factitious host, G. mellonella. An economic pest of interest was chosen because superior virulence to G. mellonella or any other host would not necessarily indicate superior virulence to the target pest. Shapiro-Ilan et al. (2003) mentioned similar debate on their comparing such beneficial traits among strains of $S$. carpocapsae for control of Curculio caryae; another target pest.

Clearly, the 3 beneficial traits investigated herein may expand the potential to control T. baal larvae, using indigenous EPNs. Foremost, EPN virulence toward the targeted and most economically important larval stage of $T$. baal on strawberry plants appears to be great (Table 1). Also, reproductive potential, and persistence among local $H$. indica populations were generally valid in the 2 tested soil types, where strawberry cultivation prevails in Egypt. While the foreign EPN Steinernema glaseri (NJ strain) proved to have superior efficacy on $T$. baal, such an efficacy had only $50 \%$ control or even less when Egyptian isolates were previously used (Shamseldean and Atwa 2004; Atwa 2009 and Atwa and Hassan 2014). In this vein, the native populations tested herein 
Table 2 Percentage mortality of Galleria mellonella last instar larvae exposed to 38 Heterorhabditids indica populations at 4 baiting times post-inoculation

\begin{tabular}{|c|c|c|c|c|c|}
\hline Population no. & 1 week & 1 month & 2 months & 3 months & Overall average \\
\hline 20 & 93.75 & 62.5 & 25 & 6.25 & 1.875ghij \\
\hline 16 & 81.25 & 25 & 0 & 0 & 1.063abcde \\
\hline 46 & 87.5 & 18.75 & 0 & 0 & 1.063abcde \\
\hline 15 & 68.75 & 31.25 & 0 & 0 & $1 \mathrm{abcd}$ \\
\hline 17 & 62.5 & 25 & 6.25 & 0 & $0.938 \mathrm{abcd}$ \\
\hline 32 & 87.5 & 43.75 & 12.5 & 0 & $1.438 \mathrm{efg}$ \\
\hline 19 & 68.75 & 37.5 & 6.25 & 0 & $1.125 \mathrm{bcde}$ \\
\hline 18 & 68.75 & 31.25 & 6.25 & 0 & 1.063abcde \\
\hline 35 & 37.5 & 31.25 & 12.5 & 0 & $0.813 a b$ \\
\hline 33 & 100 & 68.75 & 31.25 & 12.5 & $2.125 \mathrm{ij}$ \\
\hline 27 & 50 & 31.25 & 12.5 & 0 & 0.938abcd \\
\hline 26 & 56.25 & 18.75 & 6.25 & 0 & $0.813 a b$ \\
\hline 39 & 87.5 & 50 & 31.25 & 6.25 & 1.75fghi \\
\hline $37 / 2$ & 87.5 & 62.5 & 25 & 0 & 1.75fghi \\
\hline 31 & 81.25 & 37.5 & 18.75 & 6.25 & $1.438 \mathrm{efg}$ \\
\hline $4 / / 2$ & 81.25 & 43.75 & 18.75 & 6.25 & 1.5efgh \\
\hline 34 & 62.5 & 56.25 & 12.5 & 0 & $1.313 \mathrm{cdef}$ \\
\hline 5 & 93.75 & 62.5 & 37.5 & 18.75 & $2.125 \mathrm{ij}$ \\
\hline 44 & 100 & 68.75 & 31.25 & 12.5 & $2.125 \mathrm{ij}$ \\
\hline 48 & 56.25 & 31.25 & 12.5 & 0 & $1 \mathrm{abcd}$ \\
\hline 11 & 43.75 & 25 & 0 & 0 & $0.688 \mathrm{ab}$ \\
\hline $18 / 2$ & 81.25 & 68.75 & 31.25 & 6.25 & 1.875ghij \\
\hline 47 & 87.5 & 62.5 & 31.25 & 6.25 & 1.875ghij \\
\hline 60 & 68.75 & 43.75 & 25 & 0 & 1.375def \\
\hline $40 / 2$ & 75 & 25 & 6.25 & 0 & 1.063abcde \\
\hline 41 & 50 & 25 & 0 & 0 & $0.75 a b$ \\
\hline 40 & 56.25 & 25 & 6.25 & 0 & $0.875 a b c$ \\
\hline 21 & 100 & 75 & 31.25 & 12.5 & $2.188 \mathrm{ij}$ \\
\hline $6 / / 2$ & 87.5 & 62.5 & 37.5 & 6.25 & 1.938hij \\
\hline 50 & 62.5 & 25 & 0 & 0 & $0.875 a b c$ \\
\hline 22 & 100 & 68.75 & 25 & 12.5 & 2.063ij \\
\hline 43 & 62.5 & 25 & 0 & 0 & $0.875 a b c$ \\
\hline 25 & 100 & 75 & 31.25 & 18.75 & $2.25 j$ \\
\hline 58 & 56.25 & 25 & 0 & 0 & $0.813 a b$ \\
\hline 7 & 43.75 & 18.75 & 0 & 0 & $0.625 a$ \\
\hline 38 & 56.25 & 37.5 & 12.5 & 0 & 1.063abcde \\
\hline 29 & 56.25 & 31.25 & 6.25 & 0 & 0.938abcd \\
\hline 6 & 75 & 50 & 12.5 & 0 & 1.375def \\
\hline
\end{tabular}

*Average number of infected insects out of four; a cup contained 4 insects with 4 cups (replicates) per a population at each baiting time. Averages followed by same letter(s) are not significantly $(P \leq 0.05)$ different according to the Duncan's multiple range test

had good effect comparable to or even better than $S$. glaseri NJ. Successful biocontrol with EPNs should rely on nematode-host matching and economics (e.g., Laznik et al. 2010 and Abd-Elgawad 2017b). Large size of $S$. glaseri, however, reduces its mass-production yield, making this species significantly more expensive to produce than other species. Also, tendency to occasionally "lose" its bacterial symbiont is bothersome. Moreover, the 


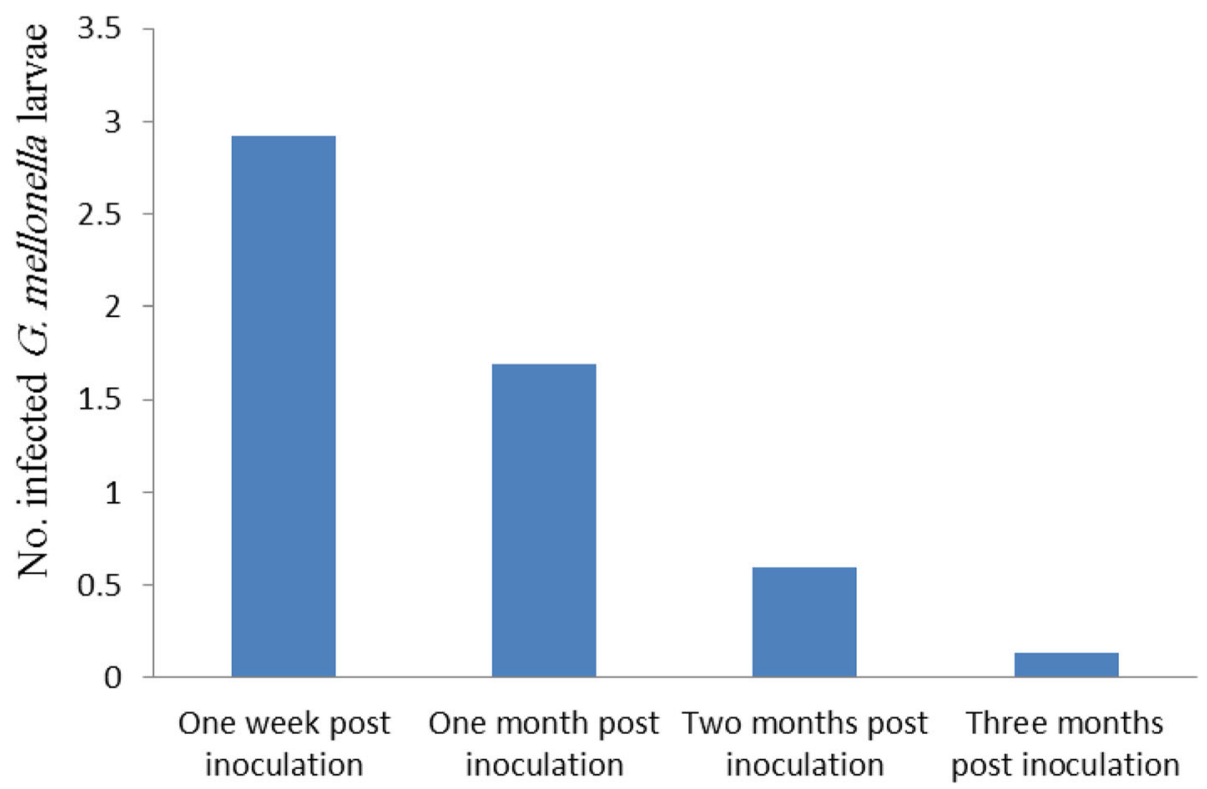

Fig. 4 Average mortality out of four Galleria mellonella larvae exposed to 38 Heterorhabditids indica populations in soil at increased postnematode inoculation periods. Numbers among all post-inoculation days are significantly $(P \leq 0.05)$ different according to DNMRT

highly active and robust $S$. glaseri-IJs are difficult to contain within formulations that rely on partial nematode dehydration (Shapiro-Ilan and Gaugler 2019). On the other hand, indigenous EPNs should be favored since they are likely more adaptive without any risk to Egyptian fauna and flora. Also, H. indica is considered to be a heat tolerant nematode (infecting insects at $30^{\circ} \mathrm{C}$ or higher). It has high yields in vivo and in vitro (Shapiro-Ilan and Gaugler 2019). This latter can compensate its short shelf life via local production, which would likely reduce transport, packaging, formulation and storage costs. For $H$. indica, only "fresh" biological agents would be applied, providing improved efficacy.

More research is needed to overcome substantial barriers to nematode control of this scarab pest, especially under field conditions (e.g., Coupland et al. 2017). Also, nematode application methods and costs may be reduced through further improvement of mass production, formulation and delivery technology (MMM et al. 2017).

\section{Conclusions}

The beneficial traits, i.e. virulence and reproductive capacity within the third instar larvae of T. baal, as well as persistence of $H$. indica populations in soil investigated herein, may expand the potential to control T. baal, using indigenous EPNs. Clearly, $H$. indica virulence toward the most economically important larval stage of $T$. baal on strawberry plants appears promising. Reproductive potential and persistence of $H$. indica populations were valid in the 2 tested soil types where strawberry commonly grows. Also, other well-known beneficial traits of $H$. indica would support its local application rather than foreign nematodes. Yet, more research is warranted to overcome barriers to nematode control of this scarab pest under field conditions.

\section{Abbreviations}

DNMRT: Duncan's new multiple range test; EPN: Entomopathogenic nematode; IJs: Infective juveniles

\section{Acknowledgements}

This study was supported in part by the US-Egypt Project cycle 17 (no. 172) entitled "Preparing and evaluating IPM tactics for increasing strawberry and citrus production." This article is derived from the Subject Data funded in part by NAS and USAID, and that any opinions, findings, conclusions, or recommendations expressed in it are those of the authors alone, and do not necessarily reflect the views of USAID or NAS.

\section{Funding}

Financial support made by US-Egypt Project fund for Project cycle 17 (no. 172) and National Research Centre, Egypt, is gratefully acknowledged.

\section{Availability of data and materials}

The datasets used and/or analyzed during the current study are available from the corresponding author on reasonable request.

\section{Authors' contributions}

All authors participated in the development and implementation of the research plan and subsequently written it. All authors read and approved the final manuscript.

Ethics approval and consent to participate

Not applicable

\section{Consent for publication}

Not applicable

Competing interests

The authors declare that they have no competing interests. 


\section{Publisher's Note}

Springer Nature remains neutral with regard to jurisdictional claims in published maps and institutional affiliations.

\section{Author details}

${ }^{1}$ Pests and Plant Protection Department, National Research Centre, Dokki, Giza 12622, Egypt. ${ }^{2}$ Plant Pathology Department, National Research Centre, El-Behoos St., Dokki, Giza 12622, Egypt. ${ }^{3}$ Citrus Research and Education Center, Institute of Food and Agricultural Sciences, University of Florida, 700 Experiment Station Road, Lake Alfred, Florida 33850, USA. ${ }^{\text {Department }}$ of Plant Protection, Faculty of Agriculture, Zagazig University, Zagazig, Egypt.

Received: 22 February 2019 Accepted: 30 April 2019

Published online: 17 May 2019

\section{References}

Abbott WS (1925) A method of computing the effectiveness of an insecticide. J Econ Entomol 18:265-267

Abd-Elgawad MMM (2017a) Comments on the economic use of entomopathogenic nematodes against insect pests. Bull NRC 41(1):66-84

Abd-Elgawad MMM (2017b) Status of entomopathogenic nematodes in integrated pest management strategies in Egypt. In: Abd-Elgawad MMM, Askary TH, Coupland J (eds) Biocontrol agents: entomopathogenic and slug parasitic nematodes. CAB International, Wallingford, pp 473-501

Abd-Elgawad MMM (2019) Plant-parasitic nematodes of strawberry in Egypt: a review. Bull NRC 43:7. https://doi.org/10.1186/s42269-019-0049-2

Abd-Elgawad MMM, Abdel-Razek AS, Abd El-Wahab AE (2012) Efficacy of kaolin, entomopathogenic nematodes and fungi on the Mediterranean fruit fly infecting citrus. Egypt J Agronematol 11(1):178-192

Abdel-Razek AS, Abd-Elgawad MMM (2013) Effects of entomopathogenic nematodes on suppressing hairy rose beetle, Tropinota squalida Scop. (Coleoptera: Scarabaeidae) population in cauliflower field in Egypt. Int J Biol Life Sci Eng 7:28-32

Atkins SD, Clark IM, Pande S, Hirsch PR, Kerry BR (2005) The use of real-time PCR and species-specific primers for the identification and monitoring of Paecilomyces lilacinus. FEMS Microbiol Ecol 51:257-264

Atwa AA (2009) Comparison between inoculative and inundative release for controlling scarab beetles in strawberry using entompathogenic nematodes under field conditions. Bull Fac Agric, Cairo Univ 60(2):197-205

Atwa AA, Hassan SH (2014) Bioefficacy of two entomopathogenic nematodes against Spodoptera littoralis Boisduval (Lepidoptera) and Temnorhynchus baal Reiche (Coleoptera) larvae. J Biopest 7(2):104-109

Baiocchi T, Abd-Elgawad MMM, Dillman AR (2017) Genetic improvement of entomopathogenic nematodes for enhanced biological control. In: AbdElgawad MMM, Askary TH, Coupland J (eds) Biocontrol agents: entomopathogenic and slug parasitic nematodes. CAB International, Wallingford, pp 505-517

Campos-Herrera R, Johnson E, El-Borai FE, Stuart RJ, Graham JH, Duncan LW (2011) Long-term stability of entomopathogenic nematode spatial patterns measured by sentinel insects and real-time PCR assays. Ann Appl Biol 158:55-68

Caveness FE (1964) A glossary of nematological terms. International institute of Tropical Agriculture Press, Nigeria.

Coupland J, Abd-Elgawad MMM, Askary TH (2017) Beneficial nematodes and the changing scope of crop protection. In: Abd-Elgawad MMM, Askary TH, Coupland J (eds) Biocontrol agents: entomopathogenic and slug parasitic nematodes. CAB International, Wallingford, pp 26-42

El-Shemy AA, Khafagy YS, Al-Genteery AMM (2013) Cultivation and production of strawberry. Techn issue no. 9/2013, General Directorate of Agricultural Culture. Egyptian Ministry of agriculture, Giza, p 135 (in Arabic)

FAO (2019) Countries by commodity. Available at: http://www.fao.org/faostat/en/ \#rankings/countries_by_commodity (Accessed 10 Mar 2019

Griffin CT (2015) Behaviour and population dynamics of entomopathogenic nematodes following application. In: Campos-Herrera R (ed) Nematodes pathogenesis of insects and other pests. Springer Int Publ, Neuchâtel, pp 57-95

Kajuga J, Hategekimana A, Yan X, Waweru BW, Li H, Li K, Yin J, Cao L, Karanja D, Umulisa C, Toepfer S (2018) Management of white grubs (Coleoptera: Scarabeidae) with entomopathogenic nematodes in Rwanda. Egypt J Biol Pest Cont 28:2. https://doi.org/10.1186/s41938-017-0003-2

Kaya HK, Stock SP (1997) Techniques in insect nematology. In: Lacey LA (ed) Manual of techniques in insect pathology. Academic Press, San Diego, pp $281-324$
Koppenhöfer AM, Fuzy EM (2008) Early timing and new combinations to increase the efficacy of neonicotinoid-entomopathogenic nematode (Rhabditida: Heterorhabditidae) combinations against white grubs (Coleoptera: Scarabaeidae). Pest Manag Sci 64:725-735

Laznik Ž, Tóth T, Lakatos T, Vidrih M, Trdan S (2010) Control of the Colorado potato beetle (Leptinotarsa decemlineata [say]) on potato under field conditions: a comparison of the efficacy of foliar application of two strains of Steinernema feltiae (Filipjev) and spraying with thiametoxam. J PI Dis Prot 117:129-135

Majić I, Sarajlić A, Lakatos T, Tóth T, Raspudić E, Puškadija Z, Kanižai Šarić G, Laznik Ž (2019) Virulence of new strain of Heterorhabditis bacteriophora from Croatia against Lasioptera rubi. PI Prot Sci 55:134-141

Abd-Elgawad MMM (2017) In: Askary TH, Coupland J (eds) Biocontrol agents: entomopathogenic and slug parasitic nematodes. CAB International, Wallingford

Pelczar MJ, Reid RD (1972) Microbiology. The McGraw-Hill Companies, USA

Shamseldean MM, Atwa AA (2004) Laboratory and field tests of entomopathogenic nematodes against the scarab beetle Temnorhynchus baal (Reiche): a novel insect pest of strawberry in Egypt. Egypt J Biol Pest Cont 14(1):127-133

Shapiro-Ilan DI, Gaugler R (2019) Nematodes (Rhabditida: Steinernematidae \& Heterorhabditidae). In: Shelton A (ed) Biological Control: A Guide to Natural Enemies in North America Available at: https://biocontrol.entomology.cornell. edu/pathogens/nematodes.php (Accessed 9 Feb 2019)

Shapiro-llan DI, Stuart R, McCoy CW (2003) Comparison of beneficial traits among strains of the entomopathogenic nematode, Steinernema carpocapsae, for control of Curculio caryae (Coleoptera: Curculionidae). Biol Control 28:12-136

Shields EJ (2015) Utilizing persistent entomopathogenic nematodes in a conservation or a more classical biological control. In: Campos-Herrera R (ed) Nematodes pathogenesis of insects and other pests. Springer Int Publ, Neuchâtel, pp 165-184

Somasekhar N, Grewal PS, Klein MG (2002) Genetic variability in stress tolerance and fitness among natural populations of Steinernema carpocapsae. Biol Control 23:303-310

Testa AM, Shields EJ (2017) Low labor "in vivo" mass rearing method for entomopathogenic nematodes. Biol Control 106:77-82

Voglar GE, Mrak T, Križman M, Jagodič A, Trdan S, Laznik Ž (2019) Effect of contaminated soil on multitrophic interactions in a terrestrial system. Plant Soil 435:337-351

\section{Submit your manuscript to a SpringerOpen ${ }^{\circ}$ journal and benefit from:}

- Convenient online submission

- Rigorous peer review

- Open access: articles freely available online

High visibility within the field

- Retaining the copyright to your article

Submit your next manuscript at $\boldsymbol{\nabla}$ springeropen.com 